Review

\title{
Living Kidney Donation: Practical Considerations on Setting Up a Program
}

\author{
Maria Irene Bellini ${ }^{1,2, *(\mathbb{D})}$, Vito Cantisani ${ }^{3}$, Augusto Lauro ${ }^{2}$ and Vito D'Andrea $^{2}$ (D) \\ 1 Azienda Ospedaliera San Camillo Forlanini, 00152 Rome, Italy \\ 2 Department of Surgical Sciences, Sapienza University of Rome, 00161 Rome, Italy; \\ augustola@yahoo.com (A.L.); vito.dandrea@uniroma1.it (V.D.) \\ 3 Department of Radiological, Oncological, and Pathological Sciences, Sapienza University of Rome, \\ 00161 Rome, Italy; vito.cantisani@uniroma1.it \\ * Correspondence: m.irene.bellini@gmail.com
}

Citation: Bellini, M.I.; Cantisani, V.;

Lauro, A.; D’Andrea, V. Living

Kidney Donation: Practical

Considerations on Setting Up a Program. Transplantology 2021, 2, 75-86. https://doi.org/doi:10.3390/ transplantology2010008

Academic Editors: Camilo

G. Sotomayor and Andrea Lauterio

Received: 28 January 2021

Accepted: 5 March 2021

Published: 10 March 2021

Publisher's Note: MDPI stays neutral with regard to jurisdictional claims in published maps and institutional affiliations.

Copyright: (c) 2021 by the authors. Licensee MDPI, Basel, Switzerland. This article is an open access article distributed under the terms and conditions of the Creative Commons Attribution (CC BY) license (https:// creativecommons.org/licenses/by/ $4.0 /)$.

\begin{abstract}
Living kidney donation represents the best treatment for end stage renal disease patients, with the potentiality to pre-emptively address kidney failure and significantly expand the organ pool. Unfortunately, there is still limited knowledge about this underutilized resource. The present review aims to describe the general principles for the establishment, organization, and oversight of a successful living kidney transplantation program, highlighting recommendation for good practice and the work up of donor selection, in view of potential short- and long-terms risks, as well as the additional value of kidney paired exchange programs. The need for donor registries is also discussed, as well as the importance of lifelong follow up.
\end{abstract}

Keywords: living donation; kidney paired exchange program; living donor risk; living donor selection

\section{Introduction}

End stage renal disease (ESRD) is a common health problem, affecting over 2 million people worldwide [1], mainly as a result of diabetic nephropathy, given the constant increase in body mass index (BMI) and median age of the general population [2]. Kidney transplantation represents the best renal replacement therapy (RRT), offering a gained survival benefit, improved quality of life, and overall reduced society costs, in comparison with the alternative treatment, namely dialysis.

However, owing to a severe discrepancy between organ offer and waitlist demand, we are far from reaching self-sufficiency, resulting in hundreds of patients dying every year from this organ shortage. Living kidney donation not only offers the recipient the best opportunity of success in terms of definitive RRT, but also represents a concrete way to preemptively address kidney failure, without facing the burden of dialysis. Furthermore, the expansion of the donor's pool also shortens the waiting list for a deceased donor transplant.

Unfortunately, there is still limited awareness about eligibility to donate a kidney from a relative or a friend, either to a specific patient or for unspecified (altruistic) donation. Additionally, programs like paired and pooled schemes are not universally present, being introduced only in the last few decades and predominantly active in the United Kingdom, Netherlands, and the USA.

The aim of this review is to provide principles for the establishment, organization, and oversight of living donor (LD) transplantation, in order to increase the awareness of this underutilised resource.

\section{General Principles: Rationale to Advocate for Living Donation}

The first successful kidney transplant was performed in the United States in 1954 by Joseph Murray. It was from an LD, Ronald Herrick, and was directed to his twin brother, Richard. Since then, living donation has become an essential part of transplantation, 
particularly for the kidney, where the demand for suitable grafts is increasing, but there are not enough organs available to satisfy this need. Living donation is considered the gold standard treatment for ESRD, offering better recipient and graft survival, as well as the psychological benefits of avoiding long waiting times before being transplanted. This particularly applies to the situation of pre-emptive transplantation, i.e., when the transplant is performed before the recipient's clinical conditions deteriorate and require dialysis to be commenced. In order to achieve a successful long-term outcome, it is recommended that recipients entering stages IV/V of kidney disease is assessed by a multi-disciplinary team, including a nephrologist, transplant surgeon, anaesthetist, and urologist (where appropriate), prior to renal transplantation, in order to seek a potential compatible donor candidate as soon as possible.

Living donation also offers patients who are more clinically complex, either immunologically or due to other co-morbidities and previous surgical conditions, the opportunity to benefit from a transplant that they might otherwise not have received from the deceased donor waiting list. More in detail, an extensive patient work-up is in fact possible, maximising in this way the chances for highly sensitised candidates to be waitlisted, particularly in the case of immunological complex cases, as in the situation of the repeated kidney re-transplantation [3]. Furthermore, another important advantage offered by LD is that an elective operation allows diligent planning and the presence of additional surgical expertise for complex cases, so it significantly increases the chances of success in comparison with an emergency out-of-our deceased kidney transplantation. Finally, as the main peculiarity of an LD itself, the kidney is retrieved from a healthy individual, thus it is intrinsically of better quality and more resistant to the occurrence and extension of the subsequent ischaemic reperfusion injury.

\section{Classification of Living Donation}

As a general principle, we could distinguish the type of LD kidney transplantation based on the relationship between the donor and recipient. We will thus consider the following:

(1) Direct donation: the donor donates to a specified recipient;

(1.1) genetically-related donation: the recipient is a blood relative;

(1.2) emotionally-related donation: the potential recipient has a pre-established social relationship (spouse, partner, friend, and so on) with the donor;

(1.3) paired-donation: a relative, friend, or partner is considered a suitable donor for a given recipient, but the pair is incompatible, thus the donor and recipient are matched with another couple in a similar situation, where the donors are compatible with the recipients of the other considered pair;

(1.4) pooled donation: the same principle as paired donation, although the pair is matched with other donors and recipients from a pool of incompatible donorrecipient pairs in order to allow multiple possible matches; pre-requisites are centralisation of the allocation and cross match procedures with an extensive informatic network to allow immunological matches in advance;

(1.5) directed altruistic donation: in this case, there is no genetic or pre-existing emotional relationship between the donor and recipient; this is most commonly the result of third-party interventions, such as, for example, social media campaigns [4].

(2) Non-directed altruistic donation: the individual donates into a paired or pooled scheme or to a recipient on the transplant waiting list. There is no documented relationship with the future recipient, who is unknown to the donor.

\section{Kidney Paired Donation (KPD) Programs}

Kidney paired donation (KPD) is a relatively recently introduced organ allocation system that has been implemented to amplify organ exchange, resulting in an intensification of the living donation process. In a KPD exchange, two or more patient-donor couples 
agree that donors incompatible or poorly matched with their respective patients will donate a kidney to another patient, with the agreement that their donation will be reciprocated on behalf of their patient. Aside from an increased possibility to get a compatible organ, KPD often provides additional benefits, including a better match in terms of blood group, tissue compatibility and age [5].

KPD was initially proposed in 1986 by Rapaport [6]. Since then, KPD has evolved and is now active in different schemes worldwide, representing one of the most promising opportunities to improve the rate of living kidney donation.

The participation of a large number of transplant centers is vital to maximise the chances to achieve better human leucocyte antigen (HLA) or age match, thus it is envisaged that even compatible pairs for their recipients are involved, in order to generate more exchange opportunities. In view of the better outcomes, it is also recommended to include HLA incompatible (HLAi) pairs in preference to antibody removal, as well as $\mathrm{ABO}$ incompatible (ABOi) pairs to avoid the costs and higher risks associated with desensitization programs, or at least by registering them for a number of runs in the KPD before choosing these alternative treatments [7]. This applies specifically to children, where getting a well-matched kidney as early as possible is fundamental to preserve the long-term outcome, reducing the chances of sensitisation and being dialysis-dependent in the future to the minimum.

Other effective ways to implement KPD are the inclusion of altruistic (unspecified) donors to trigger KPD chains; multiple registrations of potential donors for a single candidate; and the extension of the length of the exchanges, potentially also considering deceased donor kidneys as chain-initiating kidneys [8].

\section{Donor Selection}

Protection of the LD is the foremost priority when considering setting up a living kidney transplantation program. First do not harm is the general principle applied to medical practice, although we might consider this particular case as an exception from the general rule. LDs are in fact healthy individuals by definition, who voluntarily undergo surgery and the loss of a functioning kidney to help another person. It is thus mandatory to avoid at any cost additional damage by their generous act.

The evaluation and selection of the donor must thus comply with a rigorous process. The transplant community established, through the Amsterdam Forum [9], a general set of criteria in order to consider a healthy individual eligible for donation. These principles are also expressed in the Improving Global Outcomes (KDIGO) Clinical Practice Guideline on the Evaluation and Care of Living Kidney Donors [10].

A summary of the most common pre-donation screening is reported below:

(a) Renal function: Donor selection is based mainly on the view of the associated risk to develop end stage renal disease post donation, strongly based on the estimated glomerular filtration rate (eGFR), as a marker of kidney function. eGFR could be evaluated using several methods, including estimating equations and clearance measurements. The gold standard for the measurement of GFR is urinary clearance of an ideal filtration marker, defined as a substance that is freely filtered at a glomerular level and not reabsorbed, secreted, synthesized, or metabolized by the tubules, without altering kidney function. The classic method consisted of the use of urinary clearance of inulin [11]. GFR can be also estimated from serum levels of endogenous filtration markers without clearance measurements, such as creatinine, although these estimates lack the same accuracy of direct GFR measurement to evaluate candidates for kidney donation. When reference methods for direct GFR measurement are not available, it is generally recommended that a strategy based on age-adapted eGFR values estimated with either the Chronic Kidney Disease Epidemiology Collaboration (CKD-EPI) or full age spectrum (FAS) equation are acceptable [12], along with the overall medical condition. Two eGFR thresholds are considered: a high threshold $\left(90 \mathrm{~mL} / \mathrm{min}\right.$ per $\left.1.73 \mathrm{~m}^{2}\right)$ for young and healthy individuals with otherwise unremark- 
able medical conditions, and a low threshold $\left(60 \mathrm{~mL} / \mathrm{min}\right.$ per $\left.1.73 \mathrm{~m}^{2}\right)$, according to the definition of Chronic kidney disease of stage III. These values are flexible in any case, as it is in fact generally accepted that the eGFR declines with aging (Table 1) [13], independently from the presence of chronic kidney disease; therefore, the overall medical condition is always recommended to be screened for donor selection. Thus, potential donor candidates with eGFR $60-89 \mathrm{~mL} / \mathrm{min}$ per $1.73 \mathrm{~m}^{2}$ could still be considered and the decision to proceed will rely on the work up to exclude additional risk factors to develop ESRD.

Table 1. Identification of age-related kidney function safe thresholds to donate.

\begin{tabular}{ccc}
\hline \multirow{2}{*}{ Age (Years) } & \multicolumn{2}{c}{ Threshold GFR $\left(\mathbf{m L} / \mathbf{m i n} / \mathbf{1 . 7 3} \mathbf{~ m}^{\mathbf{2}}\right)$} \\
\cline { 2 - 3 } & Male & Female \\
\hline $20-29$ & 90 & 90 \\
\hline $30-34$ & 80 & 80 \\
\hline 35 & 80 & 80 \\
\hline 40 & 80 & 80 \\
\hline 45 & 80 & 80 \\
\hline 50 & 80 & 80 \\
\hline 55 & 80 & 75 \\
\hline 60 & 76 & 70 \\
\hline 65 & 71 & 64 \\
\hline 70 & 67 & 59 \\
\hline 75 & 63 & 54 \\
\hline 80 & 58 & 49 \\
\hline
\end{tabular}

With regards to recipient's kidney function, Chronic Kidney Disease Epidemiology Collaboration (CKD-EPI) or Modification of Diet in Renal Disease (MDRD) equations are generally accepted as equally effective to assess kidney function in end stage renal disease patients; a pre-emptive work up, particularly when eGFR is close to $20 \mathrm{~mL} / \mathrm{min}$ per $1.73 \mathrm{~m}^{2}$, is recommended.

(b) Hypertension: the definition and robustness of hypertension diagnosis varies, with some centres relying heavily on medication lists and others investigating the use of ambulatory blood pressure measurements (ABPMs). Patients with blood pressure (BP) values controlled up with two medications by ABPM with values ranging from $\leq 140$ to $90 \mathrm{mmHg}$ are still acceptable as donors if they keep a healthy lifestyle, do not have other comorbidities, and control their body weight. To date, there is still no generalizable association between hypertension and long-term overall mortality or cardiovascular mortality after living kidney donation, owing to the lack of a wellmatched control group, which should ideally be potential donor candidates already screened for donation, but who withdrew consent before proceeding [14]. It is well accepted that living kidney donors are healthier than the unscreened population, thus their overall cardiovascular and mortality risk does not seem to be increased and post-donation hypertension risk varies with baseline donor traits. Blood pressure may rise anyway with aging, and donation may accelerate the rise in blood pressure, so a healthy diet, smoking abstinence, achievement of healthy body weight, and regular exercise according to guidelines for the general population are recommended.

(c) Obesity: most centers consider a body mass index (BMI) value $>35 \mathrm{~kg} / \mathrm{m}^{2}$ as a contraindication for donation. The rationale of the above-mentioned choice lies in the glomerular hyperfiltration process underlying this pathological condition. Yet, BMI per se is not considered a reliable cut-off to exclude a large proportion of the general 
population, with several studies demonstrating its inaccuracy in correlation to the true differentiation between lean and fat mass. A more comprehensive evaluation considering the overall associated comorbidities is always recommended [2,4].

(d) Proteinuria: $24 \mathrm{~h}$ urine protein of $>300 \mathrm{mg}$ is considered a contraindication to donate. KDIGO guidelines recommend to assess albuminuria using the albumin-to-creatinine ratio in an untimed urine specimen and to confirm albuminuria with the albumin excretion rate (AER) in a timed urine specimen or by repeating the albumin-to creatinine ratio if AER cannot be obtained [15]. Microalbuminuria determination may be a more reliable marker of renal disease, but its value as an international standard of evaluation for kidney donors has not been uniformly ascertained.

(e) Hematuria: patients with persistent microscopic haematuria should not be considered for kidney donation unless urine cytology and a complete urologic work up are performed. Persistent microscopic hematuria is defined if a more than two to five red blood cells per high-power field of urinary sediment on two to three separate occasions are detected, with no relation to exercise, trauma, sexual activity, or menstruation [16]. If urological malignancy is excluded, a kidney biopsy may be indicated to rule out a misdiagnosed glomerular pathology. Correctable causes such as urinary tract infection or nephrolithiasis may still be acceptable for donation, if there is evidence of resolution.

(f) Diabetes: individuals with a history of diabetes or fasting blood glucose $\geq 126 \mathrm{mg} / \mathrm{dL}$ $(7.0 \mathrm{mmol} / \mathrm{L}$ ) on at least two occasions (or $2 \mathrm{~h}$ glucose with an oral glucose tolerance test $\geq 200 \mathrm{mg} / \mathrm{dL}(11.1 \mathrm{mmol} / \mathrm{L})$ ) should not be considered for donation. $\mathrm{HbA} 1 \geq 6.5 \%$ should be considered as a contraindication on the basis of established criteria for the general population.

(g) Stone disease: urolithiasis in potential LDs represents a significant challenge [17]. Historically, patients wishing to donate their kidneys were deemed ineligible if preoperative imaging demonstrated nephrolithiasis due to the risk of complications that may be related to the stone itself or to the procedure of stone removal, including infections, upper urinary tract obstruction and graft loss. However, subjects with small asymptomatic incidentally discovered stones represent a considerable percentage that might actually safely expand the donor pool. Criteria of acceptance are as follows:

$>\quad$ No concomitant hypercalciuria, hyperuricemia, or metabolic acidosis.

$>\quad$ No cystinuria or hyperoxaluria.

$>\quad$ No urinary tract infection.

$>\quad$ Multiple stones or nephrocalcinosis not evident on imaging.

Donor candidates and donors with current or prior kidney stones should follow general population, evidence-based guidelines for the prevention of disease recurrence.

(h) Malignancy: prior history of the following malignancies usually excludes living kidney donation: melanoma, testicular cancer, renal cell carcinoma, choriocarcinoma, haematological malignant disorders, bronchial cancer, breast cancer, and monoclonal gammopathy. A prior history of malignancy may only be acceptable for donation if prior treatment of the malignancy does not decrease the renal reserve or place the donor at increased risk for ESRD. If the specific cancer is curable and potential transmission of cancer can reasonably be excluded, there is no contraindication to donate; this applies also in the consideration of the higher risk to die on dialysis than with certain types of cancer [18].

(i) A particular consideration is to be reserved for donor candidates with high-grade Bosniak renal cysts (III or higher) or small (T1a) renal cell carcinoma curable by nephrectomy. In this case, they may be acceptable for donation on a case-by-case basis [19].

(j) Urinary tract infections: the donor urine should be sterile before donation and asymptomatic bacteriuria should be treated pre-donation. Pyuria and haematuria at the proposed time of donation are both contraindications that necessitate further donor work up for diagnosis and treatment. 
(k) Determination of cardiovascular risk: the clinical predictors of an increased perioperative cardiovascular risk (for non-cardiac surgery) by the American College of Cardiology / American Hospital Association [20] standards fall into three categories: major, intermediate, and minor. As major predictors, the following are considered: unstable coronary syndromes, decompensated heart failure, significant arrhythmias, and severe valvular disease. These are contraindications to living kidney donation. Most of the intermediate predictors, such as mild angina, previous myocardial infarction, and compensated or prior heart failure, are also contraindications to donation. With regards to minor predictors, older age, abnormal electrocardiography, rhythm other than sinus, low cardiac functional capacity, history of stroke, or uncontrolled hypertension, it is advisable to comprehensive medically evaluate the potential candidate, as there is no strict contraindication [21].

(1) Smoking cessation: highly recommended, as a principle for patients undergoing elective surgical procedures under general anesthesia.

(m) Cessation of alcohol abuse: $60 \mathrm{gm}$ of alcohol/day sustained over $\geq 6$ months should be avoided for a minimum of 4 weeks to decrease the known risk of postoperative morbidity.

(n) Pregnancy: current pregnancy is a contraindication to donate: in female donors, there is a higher relative risk (RR) of pre-eclampsia, estimated as 2.12, i.e., 6 per 100 versus less than 3 per 100 in the non-donor population. Furthermore, women with childbearing potential should be informed of the need to avoid becoming pregnant from the time of approval for donation to the time of recovery after donation [22].

\section{Surgical Options for Living Donor Nephrectomy}

The surgical option choice to perform LD nephrectomy is mainly determined by the center's expertise and the viability of extraction and selection of the appropriate kidney to retrieve.

Donor's past medical and surgical history plays a key role in determining the risk and difficulty of the surgery. Previous abdominal surgeries, the presence of intestinal adhesions, and the level of the dissection with a consequent risk of injury to abdominal organs need consideration when selecting which kidney to be extracted and by which modality. Under equal conditions and with similar vascularisation, generally, a left nephrectomy is preferred in living donation as it provides a longer renal vein, which eases implantation, although there is now good evidence that right nephrectomy has comparable outcomes, too [23].

Surgical techniques recommended are those minimally invasive, in view of the lower impact on donor's morbidity, in comparison with the traditional open approach. Recommended approaches are, therefore, mini-open, laparoscopy (full or hand-assisted), and retroperitoneoscopy $[24,25]$. More recently, robotic-assisted living donor nephrectomy has been showing the best outcomes in the prevention of excessive manipulation of the kidney during the extraction, but there is a higher overall cost, thus significantly limiting its implementation [26].

Since the introduction of the laparoscopic technique by Ratner in 1995, more centers have increased their living donor activity, given its numerous advantages, namely, reduced blood loss, decreased tissue trauma, lower analgesic requirements, faster resumption of food intake, shorter hospitalization, quicker return to work, and better postoperative cosmetic appearance [27]. The disadvantages of a longer learning curve and a longer operative time have been partially overcome by the hand-assisted variance introduction, meaning the insertion of the hand throughout the surgery process to facilitate surgical manoeuvres and provide greater safety by allowing immediate control of potential bleeding [23].

Although minimal invasive surgical approaches are recommended for LD nephrectomy, the final choice depends on the center's expertise and availability, in order to ensure the procedure is safe and low-risk and only carried out in specialised centers by trained professionals. 


\section{Supporting Living Donation: Where to Direct}

Optimising living kidney transplantation relies on a multidisciplinary commitment, where the progression relies heavily on the contribution from living donor coordinators. It starts from engaging with the community, through the healthcare professionals, and finally going back to the society again. There are four key components that should be considered to maximise the chances of success. These are discussed below:

I. First, the establishment of an appropriate medical, psychological, social, legal, and ethical framework for donor care is mandatory. This is to ensure high quality and safe clinical care in line with international standards and the necessary regulatory systems to prevent the potential for organ or human trafficking.

II. To provide the correct and up to date information is of paramount importance, as the whole risks and benefits of the entire procedure should be discussed with both parties: donors and patients with advanced kidney disease. Ideally, this should be done early on when the eGFR is falling, but yet $>20 \mathrm{~mL} / \mathrm{min}$, to try and catch the pre-emptive transplantation window.

III. Aside from an expert clinical and surgical team, barriers deriving from complex immunological cases could be overcome with the establishment of specific programmes such as KPD. The current available data suggest that no restriction of living kidney donation based upon the absence of an HLA match is currently considered [28].

IV. To address the current limits for expanding the living donor pool through focused research, for example, understanding the ethical and religious barriers that prevent donations in some cultures and minorities and favouring targeted campaigns to raise awareness. It would be also important to study the longer-term effects of living donor nephrectomy (i.e., $>20$ years later) with properly designed prospective databases, where the control group is formed by healthy individuals screened as potential candidates, except those who did not proceed with donation for non-medical reasons.

\section{Compensation of Living Donors}

One of the most debated current issues is the compensation of living kidney donors, outside from the mere reimbursement of expenses, translating into a net benefit for the people who donate. Yet, in this regard, a general preliminary consideration is needed. Although living kidney donors are a very much needed resource, we believe in the general principles at the basis of living kidney donation, which are altruism, meaning a selfless gift to others without expectation of remuneration, and human dignity, where any form of financial payment actually violates human dignity itself. In this view, money cannot be an incentive to donors, as a part of the human body cannot be sold according to marketing rules, not even in the name of an economic benefit for the donor or the community. This is also the thesis of the Nobel Laureate Alvin Roth, who affirmed that some transactions are not repugnant as gifts or in-kind exchanges, but become repugnant when money is involved, treating people like objects, potentially being coercive, and/or leaving some poor people open to exploitation [29].

Against the exploitation thesis, there are instead those who advocate for donors' compensation, not only to remove financial disincentives, but more actively to increase organ availability and eventually contrast the "black market" for organ selling. The idea would be to conceive a legal allocation process controlled by the government for compensation of living donors. Payment would consist in a delayed non-cash form, such as tax credits, health insurance, tuition assistance, retirement funds, and so on, so people who are desperate for cash would not be tempted to sell a kidney. In this way, achieving a waitlist self-sufficiency, even the poorest candidates who face the highest barriers to enter the waitlist would eventually benefit form a kidney transplant, and one of their major difficulties, that is, finding a relative or a friend who could donate, would be overcome [30]. 


\section{Risk to the Living Donor: Short and Long Term}

When counselling the potential LD, a checklist of all the points discussed is usually recommended. An example is provided in Table 2. In particular, it is paramount to allow enough time between the consent and the donation procedure, so that the donor has the potentiality to withdraw the consent at any time, with no consequences.

Table 2. Summary of key points to be discussed when counselling a potential living kidney donor.

(1) General points about process, consent, and confidentiality, highlighting that informed consent must be sought before progressing to each stage of the pathway and that the donor is allowed to withdraw consent at any time during the process.

(I) Information about the generic risks:
a. Death
b. General anaesthesia
c. Intraoperative damage to abdominal organs, potentiality to splenectomy, bowel/liver injury etc.
d. Post-operative ileus, use of analgesia for pain control, scarring, and long-term pain
e. Use of emo-derivates for transfusion
f. Nerval damage due to the position in theatre/chronic pain

( II) Information about specific risks, such as hypertension and end stage renal disease, to be personalised on the basis of the following:
a. Age
b. Body mass index
c. Fasting blood glucose
d. Genetic relationship to the recipient
e. Ethnicity
f. (Pre-eclampsia)

(2) Potential graft loss or impossibility to proceed with implantation in the recipient should be discussed as well; therefore, the donor should be asked if $\mathrm{s} / \mathrm{he}$
a. Wishes to donate to wait-list
b. Wishes to use the kidney for research purposes
c. Wishes to let the kidney not be used for any purpose
d. Wishes to have the kidney implanted back, although this will happen via a traditional transplantation technique, thus with another operation with a different access $\mathrm{s} /$ he underwent earlier

Living organ donation carries, in the same way as for all surgical procedures, a certain risk, with a reported mortality rate of $1 / 3000$ [31]. With regards to the morbidity, in large series of laparoscopic donor nephrectomy, the risks of intra-abdominal organ injuries and intestinal obstruction have been reported [32,33], although these are rare and predominantly associated with the transperitoneal approach. Comparing the currently used minimally invasive techniques, short-term complication rates seem to be stable at a low rate, and hand-assisted retroperitoneoscopic donor nephrectomy combines the advantages of a minimally invasive technique and manual control with the benefits of retroperitoneal access, as well as a direct and quicker approach to the vessels in the renal hilum. Thus, it appears to be safer for an early conversion in the case of bleeding [23]. In any case, with modern laparoscopic techniques, there is quicker medical and social recovery and work rehabilitation.

In terms of long-term risks for the donor, some demographic characteristics, such as, for example, high BMI, have already been discussed as potentially impairing the remnant kidney function [34]; for each unit increase in BMI above $27 \mathrm{~kg} / \mathrm{m}^{2}$, there is an associated significant 7\% increase in ESRD risk $(1.07,1.02-1.12)$. Obese LDs, therefore, have an increased short-term risk related to a more complex surgical procedure and a potential long-term risk to develop ESRD. However, there is no consensus regarding the BMI threshold for LD acceptance criteria; this is particularly important in populations where the average BMI is increasing [4]. This controversy also relates to the case for age; younger donors, with a longer time since donation and a higher eGFR at the time of donation, tend to develop a greater compensatory increase in the eGFR of the remaining kidney [35]; 
conversely, other studies show that kidney donation by older donors is relatively safe over time [36], with no age cut-off.

In general, within the transplant community, it is accepted that certain groups, such as black donors, genetically related donors, and donors to patients with immunological causes of renal failure, anyway have a higher risk of developing ESRD following donation [36,37]. Yet, it is important to stress the concept of safety in donation, as the survival and risk of ESRD for well screened LDs is similar to that of controls matched for age, gender, race, or ethnicity in the general population [22]. The overall risk of kidney failure after living kidney donation remains very low, occurring in less than 1 in $200(0.5 \%)$ donors, and it remains much less than that of the general (unscreened) population $[38,39]$.

\section{Post-Donation Follow up}

As discussed, it is vital that all LDs are appropriately informed of the potential risks and adequately followed up, ideally over their lifetime, as risk factors for ESRD tend to accumulate as the years pass by. LD coordinators are generally responsible for maintaining follow up and data collection; local health staff could be involved at different levels. Future healthcare directions will aim to minimise hospital clinic visits and ideally trace bloods and any other relevant medical event remotely via dedicated electronic applications [40]. We need in fact to remember that LDs donors are healthy individuals and not common patients who might not be willing to come to the hospitals for routine visits. Furthermore, this concept of telemedicine will save money, as the donors will not have to lose working days for medical controls.

Donor registries are equally important; each transplant centre collecting data should report them at a national authority and, where applicable, also at an international level. Recently, this seems to be the case in Europe via the realization of the EDITH project [41], the first European Living Donor Registry, with the aim to support lifelong follow up data collection.

Registry data are crucial in defining good practice in donor evaluation, benchmarking, and improving the overall quality of the process; they also allow transparency of practices and provide an easy reference for future comprehensive assessment of long-term donor risk. As an example of their utility, an accurate definition of gender- and age-specific mean and normal ranges for measured GFR in almost 3000 healthy potential U.K. living kidney donors was established via use of a large dataset and artificial intelligence. In particular, the overall analysis showed that GFR in this population remains stable in both sexes until aged around 40 years and then declines each decade at a rate of $6.6 \mathrm{~mL} / \mathrm{min} / 1.73 \mathrm{~m}^{2}$ for men and $7.7 \mathrm{~mL} / \mathrm{min} / 1.73 \mathrm{~m}^{2}$ in women [42].

Although a lifelong follow up is recommended, most centers tend to limit it to the first couple of years, when the highest decline in eGFR is expected. As a principle, follow up must start within 4-6 weeks from the procedure to ensure good recovery after the operation. This includes measurement of kidney function, early detection of complications such as wound infections, and the overall recovery of the donor, also looking at the psycho-social status, given the organ loss. Subsequently, mid- and long-term follow up are recommended on a regular basis to assess the general health status or if any complications arise, with regards to kidney function, medication and/or treatment, urinalysis, blood pressure, and so on [43].

\section{Conclusions}

In summary, the establishment of an effective LD kidney transplant programme could be judged by several parameters, significantly improving the centre performance. First, LDs offer a significant expansion of the deceased donor programme, with the chances to match highly complex candidates, thus reducing the overall waiting list time for a given centre. Secondly, there is the opportunity to optimise pre-emptive transplantation, tailoring the donor-recipient match and thus setting the scene for the best graft and patient 
outcomes. Third, an important benefit shared by the whole community is a significant saving in dialysis costs.

To keep an LD program running, a careful donor evaluation and selection is, however, mandatory, possibly recurring to independent donor advocacy to exclude any organ trafficking and the free choice to donate. Limiting living donor transplantation to high volume centers seems reasonable to minimise donor risks; appropriate perioperative shortand long-term donor follow up regimens, possibly involving data collection in the form of national and international registries, are highly recommended.

Author Contributions: Conceptualization, M.I.B.; resources, M.I.B., V.C., A.L., and V.D.; data curation, M.I.B., V.C., and V.D.; writing-original draft preparation, M.I.B.; writing-review and editing, M.I.B., V.C., A.L., and V.D. All authors have read and agreed to the published version of the manuscript.

Funding: No external source funded this study.

Institutional Review Board Statement: Not applicable.

Informed Consent Statement: Not applicable.

Data Availability Statement: The study falls under the category of research through the use of published data of existing databases.

Conflicts of Interest: The authors declare no conflict of interest.

$\begin{array}{ll}\text { Abbreviations } \\ \text { ABOi } & \text { ABO incompatible } \\ \text { ABPM } & \text { Ambulatory blood pressure measurement } \\ \text { AER } & \text { albumin excretion rate } \\ \text { BMI } & \text { body mass index } \\ \text { BP } & \text { blood pressure } \\ \text { CKD-EPI } & \text { Chronic Kidney Disease Epidemiology Collaboration } \\ \text { eGFR } & \text { estimated glomerular filtration rate } \\ \text { ESRD } & \text { end stage renal disease } \\ \text { FAS } & \text { full age spectrum } \\ \text { HLAi } & \text { human leucocyte antigen incompatible } \\ \text { LD } & \text { living donor } \\ \text { KDIGO } & \text { Kidney Disease Improving Global Outcomes. } \\ \text { KPD } & \text { kidney paired donation } \\ \text { MDRD } & \text { Modification of Diet in Renal Disease } \\ \text { RRT } & \text { renal replacement therapy }\end{array}$

\section{References}

1. World Kidney Day. Chronic Kidney Disease. Available online: https://www.worldkidneyday.org/facts/chronic-kidney-disease/ (accessed on 20 January 2021).

2. Bellini, M.I.; Paoletti, F.; Herbert, P.E. Obesity and bariatric intervention in patients with chronic renal disease. J. Int. Med. Res. 2019, 47, 2326-2341. [CrossRef] [PubMed]

3. Bellini, M.I.; Courtney, A.E.; McCaughan, J.A. living donor kidney transplantation improves graft and recipient survival in patients with multiple kidney transplants. J. Clin. Med. 2020, 9, 2118. [CrossRef]

4. Bellini, M.I.; Charalampidis, S.; Stratigos, I.; Dor, F.J.; Papalois, V. The effect of donors' demographic characteristics in renal function post-living kidney donation. analysis of a UK Single Centre Cohort. J. Clin. Med. 2019, 8, 883. [CrossRef]

5. Ferrari, P.; Weimar, W.; Johnson, R.J.; Lim, W.H.; Tinckam, K.J. Kidney paired donation: Principles, protocols and programs. Nephrol. Dial. Transplant. 2015, 30, 1276-1285. [CrossRef] [PubMed]

6. Rapaport, F.T. The case for a living emotionally related international kidney donor exchange registry. Transplant. Proc. 1986, 18 (Suppl. 2), 5-9. [PubMed]

7. Biró, P.; Haase-Kromwijk, B.; Andersson, T.; Ásgeirsson, E.I.; Baltesová, T.; Boletis, I.; Bolotinha, C.; Bond, G.; Böhmig, G.; Burnapp, L.; et al. Building kidney exchange programmes in Europe-An overview of exchange practice and activities. Transplantation 2019, 103, 1514-1522. [CrossRef] 
8. Wang, W.; Rees, M.A.; Leichtman, A.B.; Song, P.X.; Bray, M.; Ashby, V.B.; Shearon, T.; Whiteman, A.; Kalbfleisch, J.D. Deceased donors as nondirected donors in kidney paired donation. Am. J. Transplant. 2021, 21, 103-113. [CrossRef] [PubMed]

9. Ethics Committee of the Transplantation Society. The consensus statement of the Amsterdam Forum on the Care of the Live Kidney Donor. Transplantation 2004, 78, 491-492.

10. Lentine, K.L.; Kasiske, B.L.; Levey, A.S.; Adams, P.L.; Alberú, J.; Bakr, M.A.; Gallon, L.; Garvey, C.A.; Guleria, S.; Li, P.K.-T.; et al. KDIGO clinical practice guideline on the evaluation and care of living kidney donors. Transplantation 2017, 101 (Suppl. 1), S7-S105. [CrossRef] [PubMed]

11. Levey, A.S.; Inker, L.A. GFR evaluation in living kidney donor candidates. J. Am. Soc. Nephrol. 2017, 28, 1062-1071. [CrossRef] [PubMed]

12. Gaillard, F.; Courbebaisse, M.; Kamar, N.; Rostaing, L.; Jacquemont, L.; Hourmant, M.; Del Bello, A.; Couzi, L.; Merville, P.; Malvezzi, P.; et al. Impact of estimation versus direct measurement of predonation glomerular filtration rate on the eligibility of 335 potential living kidney donors. Kidney Int. 2019, 95, 896-904. [CrossRef]

13. British Transplant Society. Guidelines for Living Donor Kidney Transplantation, 4th ed.; British Transplant Society: Macclesfield, UK, 2018.

14. Deoraj, S.; Moutzouris, D.A.; Bellini, M.I. Prevalence, mechanisms, treatment, and complications of hypertension post living kidney donation. BioMed Res. Int. 2021, 2021, 1-10. [CrossRef]

15. Inker, L.A.; Huang, N.; Levey, A.S. Strategies for assessing gfr and albuminuria in the living kidney donor evaluation. Curr. Transplant. Rep. 2017, 4, 13-23. [CrossRef] [PubMed]

16. Vivante, A.; Afek, A.; Frenkel-Nir, Y.; Tzur, D.; Farfel, A.; Golan, E.; Chaiter, Y.; Shohat, T.; Skorecki, K.; Calderon-Margalit, R. Persistent asymptomatic isolated microscopic hematuria in Israeli adolescents and young adults and risk for end-stage renal disease. JAMA 2011, 306, 729-736. [CrossRef] [PubMed]

17. Longo, N.; Calogero, A.; Creta, M.; Celentano, G.; Napolitano, L.; Capece, M.; La Rocca, R.; Sagnelli, C.; Carlomagno, N.; Peluso, G.; et al. Outcomes of renal stone surgery performed either as predonation or ex vivo bench procedure in renal grafts from living donors: A systematic review. BioMed Res. Int. 2020, 2020,1-9. [CrossRef] [PubMed]

18. Naylor, K.L.; Kim, S.J.; McArthur, E.; Garg, A.X.; McCallum, M.K.; Knoll, G.A. Mortality in incident maintenance dialysis patients versus incident solid organ cancer patients: A population-based cohort. Am. J. Kidney Dis. 2019, 73, 765-776. [CrossRef]

19. Nicol, D.L.; Preston, J.M.; Wall, D.; Griffin, A.D.; Campbell, S.B.; Isbel, N.; Hawley, C.; Johnson, D.W. Kidneys from patients with small renal tumors: A novel source of kidneys for transplantation. BJU Int. 2008, 102, 188-192. [CrossRef]

20. Fleisher, L.A.; Fleischmann, K.E.; Auerbach, A.D.; Barnason, S.A.; Beckman, J.A.; Bozkurt, B.; Davila-Roman, V.G.; Gerhard-Herman, M.D.; Holly, T.A.; Kane, G.C.; et al. 2014 ACC/AHA guideline on perioperative cardiovascular evaluation and management of patients undergoing noncardiac surgery: A report of the American College of Cardiology/American Heart Association Task Force on practice guidelines. J. Am. Coll. Cardiol. 2014, 64, e77-e137. [CrossRef] [PubMed]

21. Munch, P.; Christiansen, C.F.; Birn, H.; Erikstrup, C.; Nørgaard, M. Is the risk of cardiovascular disease increased in living kidney donors? A Danish population-based cohort study. Am. J. Transplant. 2020. [CrossRef]

22. O'Keeffe, L.M.; Ramond, A.; Oliver-Williams, C.; Willeit, P.; Paige, E.; Trotter, P.; Evans, J.; Wadström, J.; Nicholson, M.; Collett, D.; et al. Mid- and long-term health risks in living kidney donors: A systematic review and meta-analysis. Ann. Intern. Med. 2018, 168, 276-284. [CrossRef]

23. Akin, E.B.; Barlas, I.S.; Dayangac, M. Hand-assisted retroperitoneoscopic donor nephrectomy offers more liberal use of right kidneys: Lessons learned from 565 cases. Transpl. Int. 2020. [CrossRef]

24. Hakim, N.S.; Papalois, V.V. A fast and safe living-donor "finger-assisted" nephrectomy technique: Results of 225 cases. Exp. Clin. Transplant. 2008, 6, 245-248. [CrossRef]

25. Bellini, M.I.; Wilson, R.S.; Veitch, P.; Brown, T.; Courtney, A.; Maxwell, A.P.; D'Andrea, V.; McDaid, J. Hyperamylasemia post living donor nephrectomy does not relate to pain. Cureus 2020, 12. [CrossRef] [PubMed]

26. Musquera, M.; Peri, L.; Ajami, T.; Revuelta, I.; Izquierdo, L.; Mercader, C.; Sierra, A.; Diekmann, F.; D'Anna, M.; Monsalve, C.; et al. Results and Lessons Learned on Robotic Assisted Kidney Transplantation. BioMed Res. Int. 2020, 2020, 1-8. [CrossRef]

27. Meinhold-Heerlein, Ivo. Laparoscopic living kidney donation. In Laparoscopy—An Interdisciplinary Approach; Dols, L.F.C., Ijzermans, J.N.M., Eds.; IntechOpen: London, UK, 2011; Available online: https:/ / www.intechopen.com/books/laparoscopy-aninterdisciplinary-approach/laparoscopic-living-kidney-donation (accessed on 4 March 2021). [CrossRef]

28. Manook, M.; Johnson, R.; Robb, M.; Burnapp, L.; Fuggle, S.V.; Mamode, N. Changing patterns of clinical decision making: Are falling numbers of antibody incompatible transplants related to the increasing success of the UK Living Kidney Sharing Scheme? A national cohort study. Transpl. Int. 2021, 34, 153-162. [CrossRef]

29. Roth, A.E. Repugnance as a constraint on markets. J. Econ. Perspect. 2007, 21, 37-58. [CrossRef]

30. Held, P.J.; McCormick, F.; Chertow, G.M.; Peters, T.G.; Roberts, J.P. Would government compensation of living kidney donors exploit the poor? An empirical analysis. PLoS ONE 2018, 13, e0205655. [CrossRef]

31. Delmonico, F.; Council of the Transplantation Society. A report of the Amsterdam forum on the care of the live kidney donor: Data and medical guidelines. Transplantation 2005, 79, S53-S66.

32. Regan, J.; Cho, E.; Flowers, J. Small bowel obstruction after laparoscopic donor nephrectomy. Surg. Endosc. 2003, 17, 108-110. [CrossRef] [PubMed]

33. Mjøen, G.; Holdaas, H.; Pfeffer, P.; Line, P.-D.; Øyen, O. Minimally invasive living donor nephrectomy-introduction of hand-assistance. Transpl. Int. 2010, 23, 1008-1014. [CrossRef] [PubMed] 
34. Locke, J.E.; Reed, R.D.; Massie, A.; MacLennan, P.A.; Sawinski, D.; Kumar, V.; Mehta, S.; Mannon, R.B.; Gaston, R.; Lewis, C.E.; et al. Obesity increases the risk of end-stage renal disease among living kidney donors. Kidney Int. 2017, 91, 699-703. [CrossRef] [PubMed]

35. Ibrahim, H.N.; Foley, R.; Tan, L.; Rogers, T.; Bailey, R.F.; Guo, H.; Gross, C.R.; Matas, A.J. Long-term consequences of kidney donation. N. Engl. J. Med. 2009, 360, 459-469. [CrossRef]

36. Dols, L.F.C.; Weimar, W.; Ijzermans, J.N.M. Long-term consequences of kidney donation. N. Engl. J. Med. 2009, $360,2371$.

37. Mjøen, G.; Hallan, S.; Hartmann, A.; Foss, A.; Midtvedt, K.; Øyen, O.; Reisæter, A.; Pfeffer, P.; Jenssen, T.; Leivestad, T.; et al. Long-term risks for kidney donors. Kidney Int. 2014, 86, 162-167. [CrossRef] [PubMed]

38. Muzaale, A.D.; Massie, A.B.; Wang, M.-C.; Montgomery, R.A.; McBride, M.A.; Wainright, J.L.; Segev, D.L. Risk of end-stage renal disease following live kidney donation. JAMA 2014, 311, 579-586. [CrossRef]

39. Najarian, J.; McHugh, L.; Matas, A.; Chavers, B. 20 years or more of follow-up of living kidney donors. Lancet 1992, 340, 807-810. [CrossRef]

40. Eno, A.K.; Thomas, A.G.; Ruck, J.M.; Rasmussen, S.E.V.P.; Halpern, S.E.; Waldram, M.M.; Muzaale, A.D.; Purnell, T.S.; Massie, A.B.; Wang, J.M.G.; et al. Assessing the attitudes and perceptions regarding the use of mobile health technologies for living kidney donor follow-up: Survey study. JMIR mHealth uHealth 2018, 6, e11192. [CrossRef] [PubMed]

41. The EDITH Project. Available online: https:// eldr.edith.eulivingdonor.eu/auth/about (accessed on 24 February 2021).

42. Fenton, A.; Montgomery, E.; Nightingale, P.; Peters, A.M.; Sheerin, N.; Wroe, A.C.; Lipkin, G.W. Glomerular filtration rate: New age- and gender- specific reference ranges and thresholds for living kidney donation. BMC Nephrol. 2018, 19, 1-8. [CrossRef] [PubMed]

43. Massie, A.B.; Leanza, J.; Fahmy, L.M.; Chow, E.K.H.; Desai, N.M.; Luo, X.; King, E.A.; Bowring, M.G.; Segev, D.L. A risk index for living donor kidney transplantation. Am. J. Transplant. 2016, 16, 2077-2084. [CrossRef] 